\title{
Evaluation of the potential anti-cancer activity of the antidepressant sertraline in human colon cancer cell lines and in colorectal cancer-xenografted mice
}

\author{
IRIT GIL-AD $^{1}$, AMICHAI ZOLOKOV ${ }^{1}$, LIAT LOMNITSKI ${ }^{2}$, MICHAL TALER $^{1}$, \\ MEITAL BAR $^{1}$, DRORIT LURIA ${ }^{1}$, EDWARD RAM ${ }^{1,3}$ and ABRAHAM WEIZMAN ${ }^{1,4}$ \\ ${ }^{1}$ Laboratory of Biological Psychiatry, Felsenstein Medical Research Center, Sackler Faculty \\ of Medicine, Tel Aviv University and Campus Rabin, Petah-Tikva 49100; ${ }^{2}$ Perrigo Israel \\ Pharmaceuticals, Bnei Brak; ${ }^{3}$ Division of General Surgery, HaSharon Hospital; \\ ${ }^{4}$ Geha Mental Health Center, Rabin Medical Center, Petah-Tikva 49100, Israel
}

Received November 12, 2007; Accepted March 11, 2008

DOI: 10.3892/ijo_00000007

\begin{abstract}
Evidence has been provided of the antiproliferative activity of certain antidepressants, mainly the selective serotonin reuptake inhibitors (SSRIs). We tested the effect of different antidepressants on cell viability and proliferation of human colorectal carcinoma cell lines HT29 and the multi-drug resistant (MDR) LS1034. The SSRIs, paroxetine and sertraline, induced a dose-dependent inhibition of cell viability and proliferation in the two cell lines $\left(\mathrm{IC}_{50}\right.$ 8-15 $\mu \mathrm{M})$. When compared to cytotoxic agents e.g. doxorubicin, vincristine and 5-fluorouracil, the SSRIs showed comparable activity (HT29) or a superior effect (LS1034). Using flow cytometry analysis, we found that the two SSRIs arrested cells at the G0/G1 stage and stimulated DNA fragmentation in a dose-dependent manner. The SSRIs (10 and $20 \mu \mathrm{M}$ ) increased caspase-3 activation. Western blot analysis showed an increase after $24 \mathrm{~h}$ in c-Jun and a decrease in the expression of the anti-apoptotic protein $\mathrm{Bcl}-2$. The results suggest a proapoptotic activity for the active SSRIs accompanied by mitogen-activated protein kinase cascade activation and Bcl-2 inhibition. In vivo, we used CD1 nude mice xenografted subcutaneously with HT29 cells. On day 8, after cell inoculation sertraline or paroxetine $(15 \mathrm{mg} / \mathrm{kg}$ x3/week i.p.) were administered to animals (6/group), which were monitored weekly (for 5 weeks) for tumor volume and body weight. At 5 weeks, the animals survived, with no significant difference in body weight. Sertraline, though not paroxetine, significantly inhibited tumor growth. Collectively, our results suggest that the widely-used antidepressant,
\end{abstract}

Correspondence to: Dr Irit Gil-Ad, Laboratory of Biological Psychiatry, Campus Rabin, Petah-Tikva 49100, Israel

E-mail: iritgil@post.tau.ac.il

Key words: antidepressants, sertraline, colorectal cancer, apoptosis sertraline, possesses a potential anti-tumor activity, which circumvents the MDR mechanism. Since SSRI therapy is frequently indicated in cancer patients, the use of sertraline in colon cancer patients with co-morbidity of depression seems attractive.

\section{Introduction}

Colorectal cancer is the third most common cancer in men and women. Patients $(\sim 20 \%)$ who have metastatic disease at the time of diagnosis, proves fatal for $50 \%$ of them. New cases $(\sim 780,000)$ are diagnosed worldwide every year $(1,2)$. Therapy includes surgery, radiotherapy and chemotherapy, mainly fluoropyrimidines (3). Defects in apoptotic pathways are common in cancer cells and play a role in tumor initiation and progression. Bcl-2 and $\mathrm{Bcl}-\mathrm{X}_{\mathrm{L}}$ are important members of a family of proteins responsible for the dysregulation of apoptosis $(4,5)$, while the p53 tumor suppressor protein inhibits cellular proliferation and induces cell cycle arrest and apoptosis. Overexpression of Bcl-2 and increased expression of the p53-mutated type have a role in the prognosis of the disease $(6,7)$. c-Jun NH2-terminal kinase $(\mathrm{JNK})$ is one of the subfamilies of mitogen-activated protein kinases (MAPKs), that phosphorylates c-Jun. JNK activation leads to the phosphorylation of c-Jun and cellular proteins and those associated with apoptosis including Bcl-2 and p53 (8). Furthermore, the inactivation of JNK1 was suggested to cause a resistance to cisplatin in ovarian cancer (9). Moreover, the blockade of the MAPK pathway by extracellular signal-regulated kinase (ERK) kinase (MEK) inhibitor was reported to suppress human and mouse colon cancer tumor growth in mice (10). Antidepressants are drugs used for the treatment of depression, anxiety and certain behavioral disorders. They are frequently prescribed for depression in cancer patients. Previous reports from our and other laboratories have shown that certain tricyclic antidepressants (TCAs), e.g clomipramine and selected selective serotonin reuptake inhibitors (SSRIs), such as paroxetine and fluoxetine, exhibit, in addition to their psychotropic effect, 
anti-proliferative effects in experimental models $(11,12)$. The underlying mechanism of the anti-depressant-induced apoptosis is unknown. Transcription factors that are members of the MAPK pathway, play a critical role in the activation of 'death genes' during apoptosis (13-15). In glioma and neuroblastoma cell lines, we previously showed that fluoxetine and paroxetine, though not imipramine and mianserin, induced a rapid increase in p-c-Jun levels, cytochrome c release from mitochondria and caspase- 3 activation, suggesting the involvement of the MAPK pathway in the proapoptotic process (12). The monocyclic SSRI fluoxetine and zimelidine were shown to inhibit the proliferation of prostate carcinoma cells (16). Clomipramine, imipramine and citalopram were found to induce apoptosis in myeloid leukemia HL-60 cells (17). In Burkitt lymphoma cells, the SSRIs paroxetine, fluoxetine and citalopram induced apoptosis accompanied by caspase activation and reversed overexpression of $\mathrm{Bcl}-2$ (18). Bcl-2 is a protein, which exerts an anti-apoptotic function and is overexpressed in many forms of cancer and contributes to tumor resistance. P53 is a tumor suppressor gene involved in apoptosis; many tumors of various origins, including colorectal cancer, are caused or at least associated with mutations in this gene.

We recently demonstrated in healthy human lymphocytes, that the SSRI, paroxetine, induced an immunosuppressive effect with the inhibition of transcription factors and the activator of transcription 3 (Stat3) and cyclo-oxygenase $($ Cox-2). The latter are involved in cell proliferation and maturation in neoplastic mechanisms (19). In line with these findings, Rossetti et al (20) reported that paroxetine, though not venlafaxine induced a marked cytotoxic effect in a wide variety of human and murine cell lines. Additionally, paroxetine induced apoptosis in human osteosarcoma cells and this effect was accompanied by the activation of p38 MAPK and caspase-3 pathways (21). In a recent epidemiological study, a significantly reduced risk of colorectal cancer was associated with a high SSRI daily intake, while no protective effect was found for tricyclic antidepressants (22). In contrast, a recent multicenter clinical trial with low-dose sertraline $(50 \mathrm{mg} / \mathrm{p} .0$.$) in patients with advanced cancer,$ failed to show a beneficial effect on survival or quality of life (23). One of the major obstacles in inducing responsiveness in cancer cells is the existence of efflux transporter Pglycoprotein (Pgp), which is linked to multi-drug resistance (MDR) genes (24). It was found that several antidepressants possess an inhibitory effect on Pgp at similar concentrations as quinidine (25). In a recent study, we showed that the neuroleptic agent thioridazine (a phenothiazine) was efficient in inhibiting the proliferation of the mouse melanoma MDR cell line (26). Another study provided evidence that the SSRI antidepressant fluoxetine enhanced responses to chemotherapy in xenografted mouse tumor models, by the inhibition of the MDR extrusion pump Pgp (27). Our study was undertaken with the aim of evaluating the potential anti-tumor effects of sertraline and paroxetine and determining the molecular mechanism underlying their proapoptotic effect in two human colon carcinoma cell lines: HT29 possessing mutated p53 and LS1034, which is a p53 negative tumor that presents MDR features $(28,29)$

\section{Materials and methods}

Sertraline-Hcl was purchased from Topharman Shanghai, China. Paroxetine-Hcl and fluoxetine-Hcl hydrochloride were kindly donated by Perrigo Pharmaceuticals (Bnei Brak, Israel). Cisplatin was obtained from Abic, Petah-Tikva, Israel. 5-Fluorouracil (5-FU), clomipramine, doxorubicin, Hoechst 33342, propidium iodide, trypsin, neutral red reagent, dithiothreitol, Hepes and glycerol were purchased from Sigma (St. Louis, MO, USA). Dulbecco's Modified Eagle's Medium (DMEM), fetal calf serum, RPMI-1640 medium, penicillin, nystatin and streptomycin were purchased from Biological Industries Ltd. (Kibbutz Beit Ha'emk, Israel). Substrate Ac-DEVD-AMC was purchased from Biomol Plymouth Meeting, PA, USA and caspase-3 inhibitor (Ac-DEVD-CHO) was obtained from Alexis (Lausen, Switzerland).

Cells. The human HT-29 and LS1034 colon adenocarcinoma cell lines were obtained from American Type Culture Collection (Manassas, Virginia, USA). The HT-29 cells were maintained in DMEM medium and the LS1034 cells in RPMI-1640 medium supplemented with $10 \%$ (v/v) heatinactivated fetal bovine serum, $100 \mathrm{U} / \mathrm{ml}$ penicillin and $0.1 \mathrm{mg} /$ $\mathrm{ml}$ streptomycin in a humidified atmosphere of $95 \%$ air and $5 \% \mathrm{CO}_{2}$ at $37^{\circ} \mathrm{C}$. Confluent cultures were washed with PBS, detached with trypsin $(0.25 \%)$, centrifuged and sub-cultured in 96-well microtiter test plates.

Cell viability was measured using neutral red staining (30). Cells were distributed in 96-well microplates $(10,000-$ $20,000 /$ well). Absorption of neutral red by lysosomes causes the coloring of living cells. Quantitative analysis was performed by a colorimetric assay (ELISA reader at $550 \mathrm{~nm}$ ). Viability was tested in cells treated with the antidepressants or the cytotoxic agent $(0-30 \mu \mathrm{M})$ and compared to vehicletreated cells (saline and lactic acid 0.01-0.05\%), which did not modify basal cell viability. Results were expressed as $\%$ of controls (vehicle-treated cells).

$\left[{ }^{3} \mathrm{H}\right]$-thymidine incorporation. $\left[{ }^{3} \mathrm{H}\right]$-thymidine incorporation was measured in $\mathrm{HT} 29$ cells using $1 \mu \mathrm{Ci} / \mathrm{ml}\left[{ }^{3} \mathrm{H}\right]$-thymidine, after the determination of linear correlation between the cell number and incorporation (31). Cells $(10,000 /$ well) were treated with paroxetine, sertraline $(10-30 \mu \mathrm{M})$ or vehicle for $24 \mathrm{~h}$, harvested and the incorporate radioactivity was determined using a liquid scintillation counter.

Flow cytometry and cell cycle. The cell cycle was studied by flow cytometric analysis of propidium iodide (PI)-stained human HT29 cells (32). Cells were treated with sertraline or paroxetine $(7.5,15$ and $30 \mu \mathrm{M})$ for $24 \mathrm{~h}$ and analyzed by a fluorescence activated cell sorter (FACS) (Becton Dickinson, Mountain View, CA) equipped with an argon ion laser adjusted to an excitation wavelength of $480 \mathrm{nM}$ and with a Doublet Discrimination Module (DDM). Lysis II (Becton Dickinson) software was used for data acquisition and the determination of apoptotic nuclear changes and cell cycle.

Fluorescence of Hoechst plus PI-stained HT29 cells. Cells were co-stained with DNA binding dyes Hoechst 33342 
$(20 \mu \mathrm{g} / \mathrm{ml})$ and PI $(10 \mu \mathrm{g} / \mathrm{ml})$ for $5 \mathrm{~min}$ at room temperature, $24 \mathrm{~h}$ after exposure to sertraline, paroxetine and doxorubicin or saline. Cells were examined with a fluorescence microscope with ultraviolet excitation at 340-380 nm. Intact nuclei of control cells were detected by typical blue Hoechst fluorescence, while cells undergoing apoptosis were detected by fragmented nuclear red PI fluorescence (33).

Caspase-3 activity was measured in LS1034 cells by an enzymatic fluorimetric method using a fluorigenic substrate (Ac-DEVD-AMC) producing blue fluorescence detected at a $360 \mathrm{~nm}$ wavelength (34). AMC was cleaved from the substrate by caspase-3 (and caspase-3-like enzymes) and produced a yellow-green fluorescence monitored by a fluorimeter at $460 \mathrm{~nm}$. The amount of the yellow green fluorescence is proportional to the activity of the caspase-3 in the cell extract sample. LS1034 lysates were prepared by Triton X-100 extraction $4 \mathrm{~h}$ after exposure to paroxetine and sertraline (10 and $20 \mu \mathrm{M})$ as compared to the control vehicle-treated cells. Whole cell lysates were added to a buffer containing $100 \mu \mathrm{M}$ peptide substrate, $100 \mathrm{mM}$ HEPES, 10\% glycerol, $1 \mathrm{mM}$ EDTA and $10 \mathrm{mM}$ dithiothreitol. Measurements were determined in duplicates every 5 min for $75 \mathrm{~min}$. The reaction was monitored after $45 \mathrm{~min}$ in the presence of a specific caspase-3 inhibitor DEVD-AMC-CHO, which was added to the reaction mixture in order to ascertain the specificity of the enzyme.

Western blot analysis. Cell extracts (HT29 or LS1034) and homogenates of HT29 tumors were extracted with a lysis buffer (150 mM NaCl, $5 \mathrm{mM}$ EDTA, 1\% Nonidet P-40, $0.5 \%$ sodium deoxycholate, $1 \mathrm{mM} \mathrm{Na} \mathrm{VO}_{4}, 200 \mathrm{mM}$ Hepes and $50 \mathrm{mM} \mathrm{NaF}$ ). Cells were incubated for $60 \mathrm{~min}$ at $4{ }^{\circ} \mathrm{C}$. The proteins were cleared by centrifugation at $14,000 \mathrm{x} \mathrm{g}$ for $20 \mathrm{~min}$ at $4^{\circ} \mathrm{C}$. Protein concentration was determined by a BCA kit (Pierce, Rockford, USA). A protein $(50 \mu \mathrm{g})$ from each sample was subjected to SDS-PAGE. Electroblotted proteins were detected using antibodies: $\beta$-actin (Chemicon, CA, USA) c-Jun, P-c-Jun, Bcl-2, p53 (Santa Cruz Biotechnology, CA, USA). Detection was carried out by horseradish peroxidase-conjugated goat anti-mouse or antimouse antibodies and enhanced chemiluminescence (Super Signal West Picochemiluminescent Substrate, Pierce, USA). Densitometry of electropherograms was carried out by means of a soft laser scanning densitometer (SLR-2D/1D; Biomed Instrument Inc., USA).

Animal studies. Male CD1 nude mice aged 5-7 weeks were purchased from Harlan, Jerusalem, Israel. The animals were housed (3-4/cage) in an ammonia-free environment in a defined and pathogen-free colony in controlled conditions (temperature, light and humidity) and given food and water ad libitum. After 7 days of acclimatization, animals were divided into 4 groups (6/group). HT-29 human colon carcinoma cells mixed in matrigel were s.c. injected on the right flank of each athymic mice $(2,000,000$ cells/mouse $)$ (35). Therapy began on day 8 after cell inoculation (sertraline, paroxetine or 5-FU $15 \mathrm{mg} / \mathrm{kg}$ i.p. each) twice a week on the first three weeks, followed by three times a week from the $3 \mathrm{rd}$ week, or with vehicle (DMSO 0.1\%) $(0.1 \mathrm{ml} / 10 \mathrm{~g} \mathrm{BW})$. Tumors were measured with a digital caliper once a week. Tumor volume was determined using the following formula:

Tumor volume $=(\text { shortest diameter })^{2} \times($ longest diameter $) \times 0.5$

Tumor volume was controlled weekly. At autopsy, tumors were dissected and frozen $\left(-70^{\circ} \mathrm{C}\right)$ until homogenates were removed for protein determination by Western blot analysis.

Statistics. Determination of cell viability and proliferation was performed using mean \pm SE of four determinations for each point. The difference between the drugs' effect on tumor volume of cancer animals was determined using the Student's $\mathrm{t}$-test and a difference of $\mathrm{p}<0.05$ was considered significant. In the FACS analysis, each point was the mean \pm SEM of 3 samples and in the caspase- 3 analysis each point (taken every $5 \mathrm{~min}$ ) is a mean of a duplicate.

Ethics. The study was approved by the Institutional Ethics Committee for Animal Experimentation at Tel Aviv University, Tel Aviv, Israel. Principles of Laboratory Animal Care were followed (see NIH publication No. 85-23, revised 1985).

\section{Results}

Fig. 1A shows the comparative effect of different antidepressants at 0-30 $\mu \mathrm{M}$ : paroxetine, sertraline and fluoxetine (SSRIs), clomipramine (TCA) and reboxetine (norepinephrine re-uptake inhibitor) on cell viability (assessed by neutral red staining) of the human colon carcinoma cell line HT29, $24 \mathrm{~h}$ after drug administration. The results show that each of the agents except reboxetine induced a dose-dependent decrease in cell viability with a potency scale of: sertraline $>$ paroxetine $>$ clomipramine $>$ fluoxetine. $\mathrm{IC}_{50}$ range of 14.7-30.4 $\mu \mathrm{M}$ (sertraline and fluoxetine, respectively).

Fig. 1B shows the comparative effect of the different antidepressants at $0-30 \mu \mathrm{M}$ as compared to 5-FU and doxorubicin at equimolar concentrations on cell viability (neutral red staining) of the human MDR colon carcinoma cell line LS1034, $24 \mathrm{~h}$ after drug administration. The results show that each antidepressant, except reboxetine, induced a dose-dependent decrease in cell viability with a potency scale of: sertraline $>$ paroxetine $>$ fluoxetine $>$ clomipramine. $\mathrm{IC}_{50}$ levels range from 13.1 to $33.3 \mu \mathrm{M}$ (sertraline and clomipramine respectively), whereas the cytotoxic agents doxorubicin and 5 -FU demonstrated very low or no activity $\left(\mathrm{IC}_{50}\right.$ of $37.8 \mu \mathrm{M}$ and $>95 \mu \mathrm{M}$, respectively).

Fig. 2 presents the effect of sertraline and paroxetine (0-30 $\mu \mathrm{M})$ in HT29 cells as compared to the widely used chemotherapeutic agents doxorubicin, vincristine and cisplatin, at an equimolar concentration, on $\left[{ }^{3} \mathrm{H}\right]$-thymidine incorporation. The data show a dose-dependent decrease in cell proliferation induced by sertraline and paroxetine $\left(\mathrm{IC}_{50}\right.$ 15.8 and $12.4 \mu \mathrm{M}$, respectively). The three cytotoxic agents induced a decrease in cell proliferation at $10 \mu \mathrm{M}$ (resembling paroxetine), followed by a plateau. The $\mathrm{IC}_{50}$ levels of the cytotoxic agents were of 19.9 and $15.3 \mu \mathrm{M}$ for cisplatin and vincristin respectively, while doxorubicin had a higher efficacy with $\mathrm{IC}_{50}<5 \mu \mathrm{M}$. 


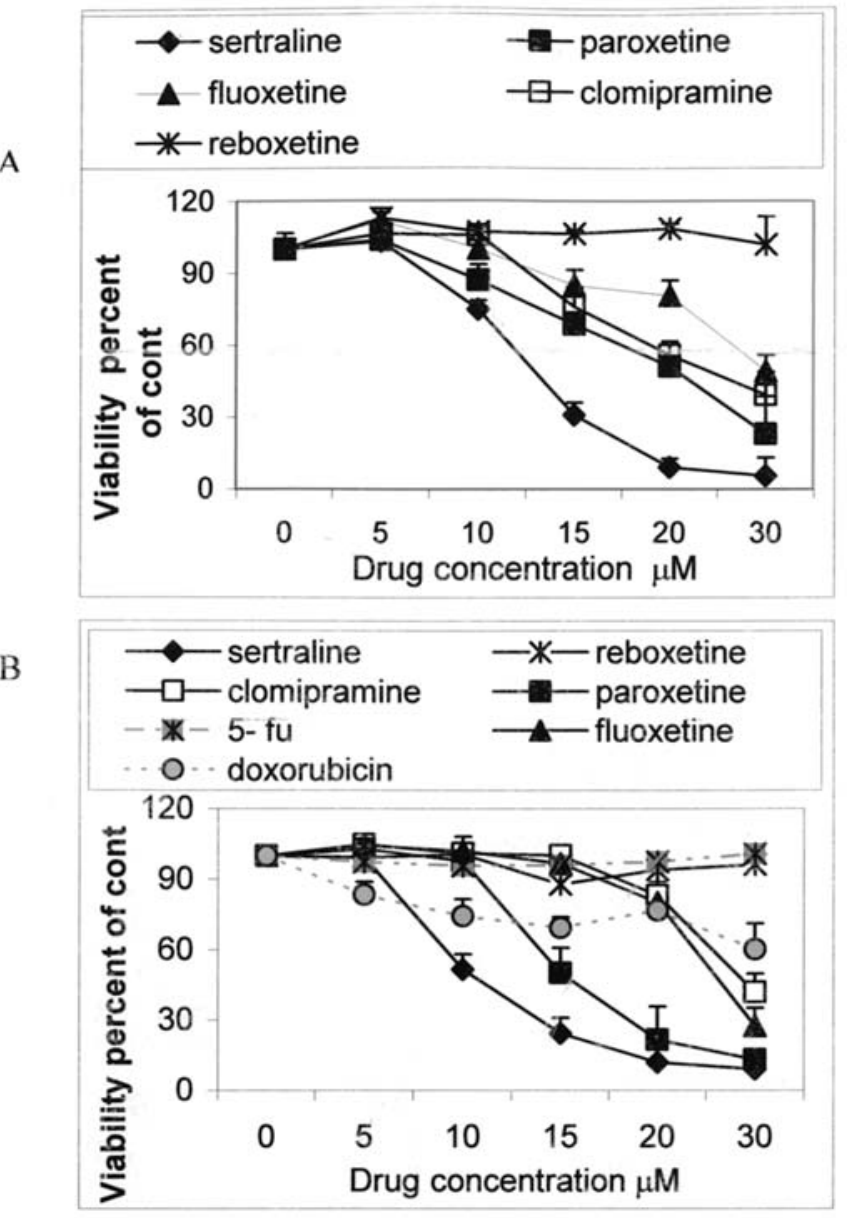

Figure 1. (A) The effect of different antidepressants (5-30 $\mu \mathrm{M})$ on the viability of the HT29 cell line. (B) The effect of different antidepressants (5-30 $\mu \mathrm{M})$ and cytotoxic drugs on the viability of the LS1034 cell line. Each point is the mean +/- SEM of 4 determinations. The results are expressed as \% of controls (saline-treated cells).

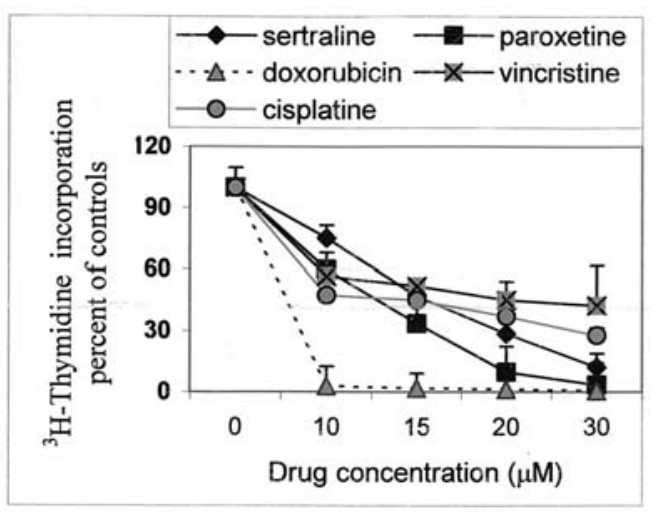

Figure 2. The effect of sertraline and paroxetine as compared to cytotoxic agents $(10-30 \mu \mathrm{M})$ on $\left[{ }^{3} \mathrm{H}\right]$-thymidine incorporation in HT29 cells. Each point is the mean \pm SEM of 4 determinations.

Fig. 3 shows the fluorescence microscope images of HT29 cells treated with paroxetine, sertraline and doxorubicin (15 and $20 \mu \mathrm{M}$ ) for $24 \mathrm{~h}$ compared to vehicle following staining with PI and Hoechst reagents. The figure demonstrates a blue (Hoechst) fluorescence of intact nuclei treated with vehicle. Red (PI) fluorescence presents fragmented nuclei of cells undergoing mainly apoptosis. The paroxetine and sertraline treated cells appeared with increased red fluorescence especially of sertraline $(20 \mu \mathrm{M})$, supporting apoptotic cell death. Doxorubicin therapy resulted in the disappearance of most of the cells in the field and a view of debris, suggesting the combination of necrotic and apoptotic cell death.

Fig. 4 shows the effect of sertraline (A) or paroxetine (B) (7.5-50 $\mu \mathrm{M}$ for $24 \mathrm{~h}$ ) on the cell cycle of HT29 cells using flow cytometry analysis of PI-stained cells. The results show that the two agents caused a dose-dependent decrease in the DNA synthesis (S) phase (34.8 vs $7.1 \%$ and $11.5 \%$ controls vs paroxetine and sertraline $50 \mu \mathrm{M}$, respectively) and arrested cells in the subapoptotic G0/G1 phase (52.49 vs $82.57 \%$ and $79.56 \%$ controls vs paroxetine and sertraline $50 \mu \mathrm{M}$, respectively).

Fig. 5 shows the time course of the substrate cleavage of cell extracts responding to caspase- 3 following exposure of $4 \mathrm{~h}$ to sertraline, paroxetine or vehicle. The reaction was performed in LS1034. Sertraline and paroxetine, in a dosedependent manner, increased the activity of caspase-3, which is a key factor in apoptosis induction. The specificity of the effect is evidenced by the blockade of the increasing activity of the enzyme shown with the addition of the caspase-3specific inhibitor DEVD-AMC-CHO.

Fig. 6A and B illustrates the expression of three key proteins Bcl-2, p53 and c-Jun exposed to the antidepressants for $24 \mathrm{~h}$ using Western blot analysis. Results show that in 


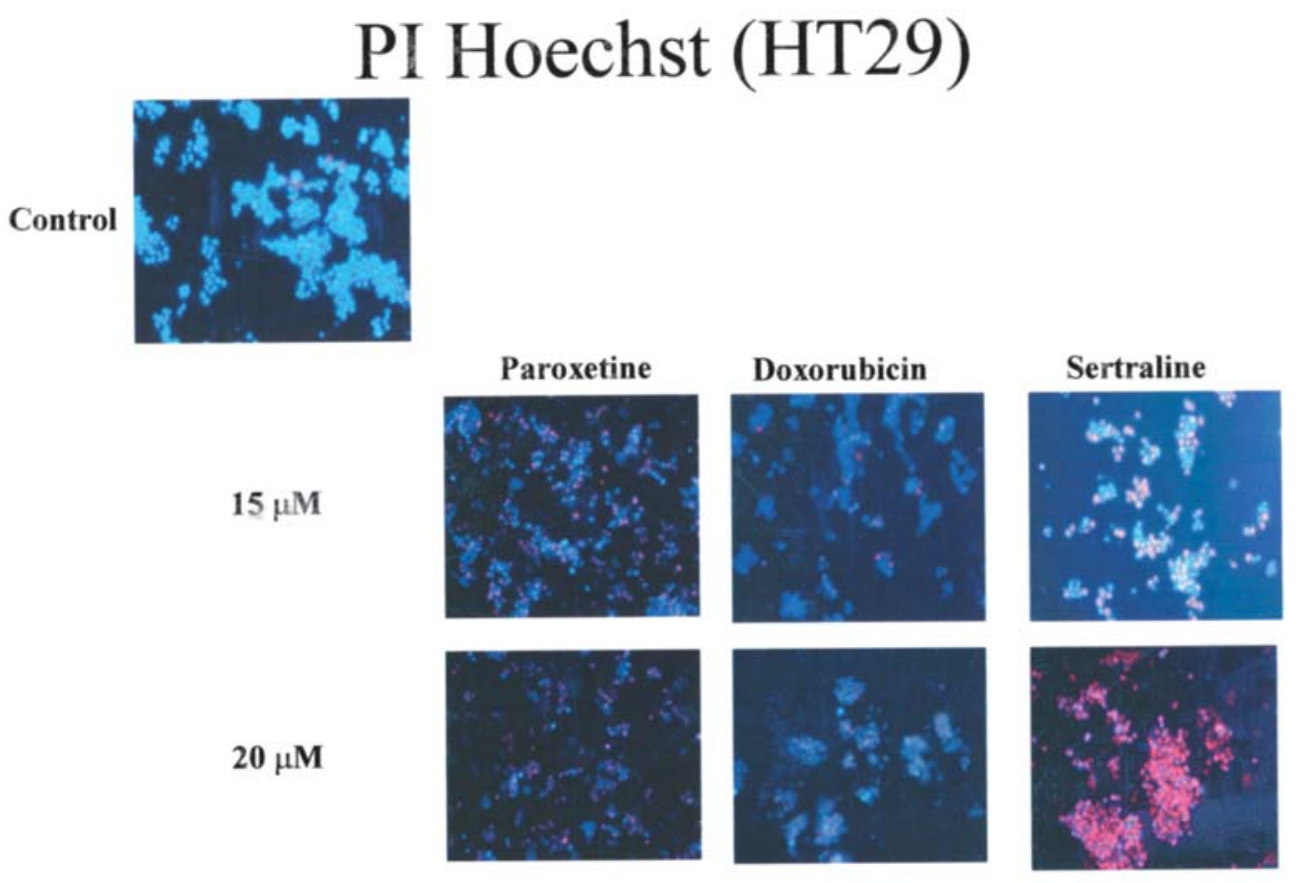

Figure 3. A fluorescence microscope image of PI (red fluorescence) + Hoechst (blue fluorescence) of HT29 cells treated with paroxetine, sertraline or doxorubicin $(15$ and $20 \mu \mathrm{M})$. Blue nuclear staining indicates intact cells (controls) and red PI defined nuclear staining indicates apoptosis (paroxetine and more potently sertraline). Undefined blue or red colors indicate debris of cells with mixed apoptosis and necrosis (doxorubicin).
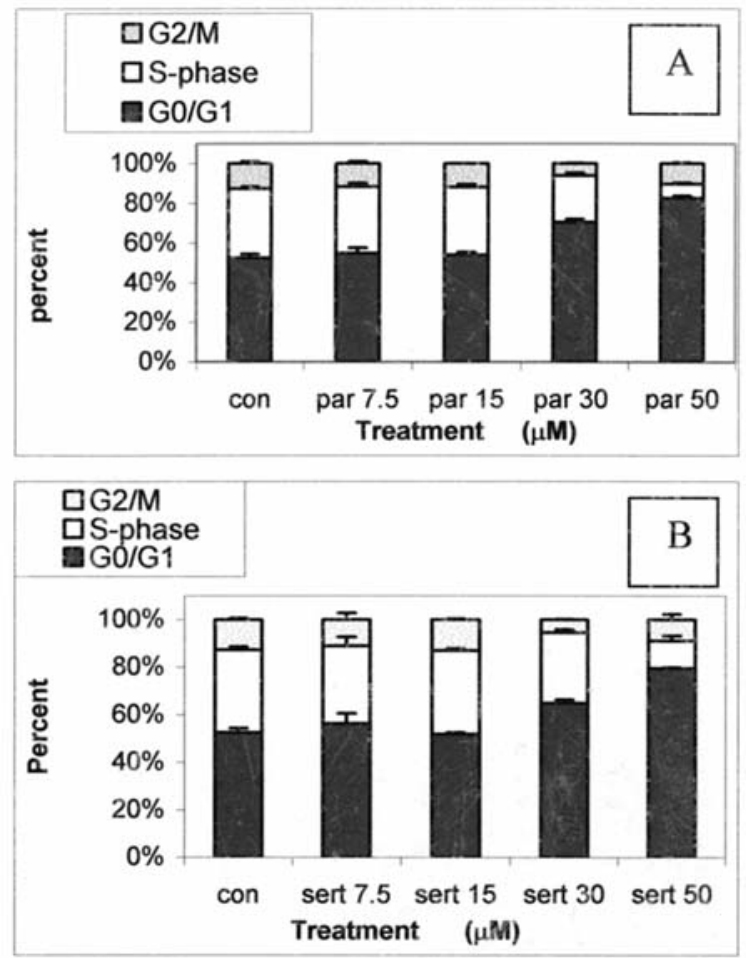

Figure 4. Flow cytometry of PI-stained HT29 cells demonstrating cell cycle after exposure of $24 \mathrm{~h}$ to paroxetine (A) or sertraline (B) each at 7.5-50 $\mu \mathrm{M}$. Each point represents the mean \pm SEM of 3 determinations.

HT29 cells, SSRIs at $20 \mu \mathrm{M}$ though not cisplatin decreased the expression of the antiapoptotic proto-oncogene, Bcl-2. When plotted by densitometry against actin (Table I), we found a 40 and $60 \%$ decrease in the p53 expression for sertraline and paroxetine, respectively. Moreover, in the
Table I. Densitometry (arbitrary units of blots protein/actin) of c-Jun, P53 and Bc12 in HT29 and LS1034 cell lines exposed to paroxetine, sertraline or a cytotoxic drug (cisplatin or doxorubicin) at 10 and $20 \mu \mathrm{M}$.

\begin{tabular}{llcl}
\hline \multicolumn{3}{l}{ HT29 cell line } & \\
\hline Drug $(\mu \mathrm{M})$ & c-Jun & P53 & Bcl2 \\
\hline Control & 0.495 & 1.946 & 1.131 \\
Paroxetine (10) & 1.079 & 1.135 & 1.434 \\
Paroxetine (20) & 1.157 & 1.976 & 0.468 \\
Sertraline (10) & 1.166 & 1.097 & 0.994 \\
Sertraline (20) & 1.439 & 1.340 & 0.794 \\
Cisplatin (10) & 0.576 & 1.697 & 1.145 \\
Cisplatin (20) & 1.281 & 1.882 & 1.039 \\
\hline & LS1034 cell line & \\
\hline Drug ( $\mu \mathrm{M})$ & $\mathrm{c}-\mathrm{Jun}$ & $\mathrm{P} 53$ & $\mathrm{Bcl}$ \\
\hline Control & & & \\
\hline Paroxetine (10) & 1.088 & 0.464 & 1.185 \\
Paroxetine (20) & 1.185 & 0.633 & 1.114 \\
Sertraline (10) & 1.569 & 0.856 & 0.846 \\
Sertraline (20) & 1.251 & 0.549 & 0.755 \\
Doxorubicin (10) & 0.656 & 1.312 & 0.537 \\
Doxorubicin (20) & 0.441 & 2.174 & 0.957 \\
\hline
\end{tabular}

LS1034 cells, we found a decrease in Bcl-2 for paroxetine and sertraline $(20 \mu \mathrm{M})(37$ and $58 \%$ of controls, respectively) and the same activity was registered with doxorubicin. In HT29 cells paroxetine and sertraline at $10 \mu \mathrm{M}$ slightly decreased 


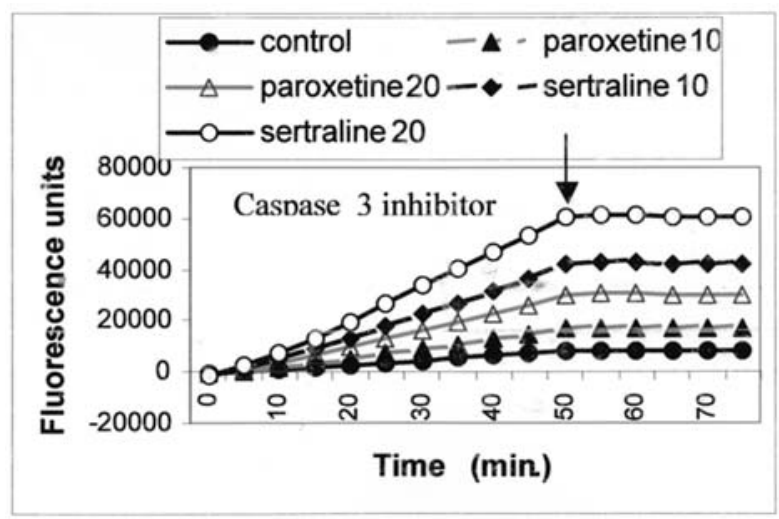

Figure 5. Caspase-3 activity in LS1034 cells exposed to sertraline or paroxetine (10 and $20 \mu \mathrm{M})$ as expressed by increased blue fluorescence (360 $\mathrm{nm}$ wavelength) induced by a substrate cleavage due to caspase- 3 activity. Determinations were performed at $5 \mathrm{~min}$ intervals for $75 \mathrm{~min}$. The caspase- 3 inhibitor was added after $45 \mathrm{~min}$.

the expression of the mutated form of p53, whereas in the LS1034 cells p53 (wild-type) expression was very weak and tended to decrease with SSRIs and increase with doxorubicin. Paroxetine and to a higher degree, sertraline (10 and $20 \mu \mathrm{M})$, markedly stimulated the expression of the MAPK protein c-Jun in the two cell lines (2.3- and 2.9-fold vs controls for paroxetine and sertraline at $20 \mu \mathrm{M}$, respectively). The same effect was found in HT29 cells using cisplatin, though not in the MDR cells LS1034 with doxorubicin, suggesting a potential role for the c-Jun pathway in the development of drug resistance.

The relationship between time and effect of sertraline, paroxetine or 5-FU compared to vehicle on tumor growth during five weeks of therapy in HT29-xenografted nude (CD1) mice, as shown in Fig. 7A. The results show a delay in tumor growth in the 2nd week only in the sertraline-treated mice. Yet, after the 3rd week of therapy, no significant difference was found in each of the tested groups. From the beginning of the 3rd week and following exposure of the animals to therapy three times weekly, we noted a sustained inhibition in tumor growth in the sertraline-treated group, resulting in a significantly lower tumor volume compared to controls after 5 weeks of therapy.

In terms of within group variation in tumor volume after 5 weeks, we found that in the control group 6/7 mice had a large tumor $\left(>500 \mathrm{~mm}^{3}\right)$, only $1 / 6$ had a large tumor in the sertraline group and $4 / 6$ and $3 / 6$ mice had large tumors in the paroxetine and the 5-FU-treated group, respectively (Table II). Body weight gain did not differ between the different groups

\section{A}
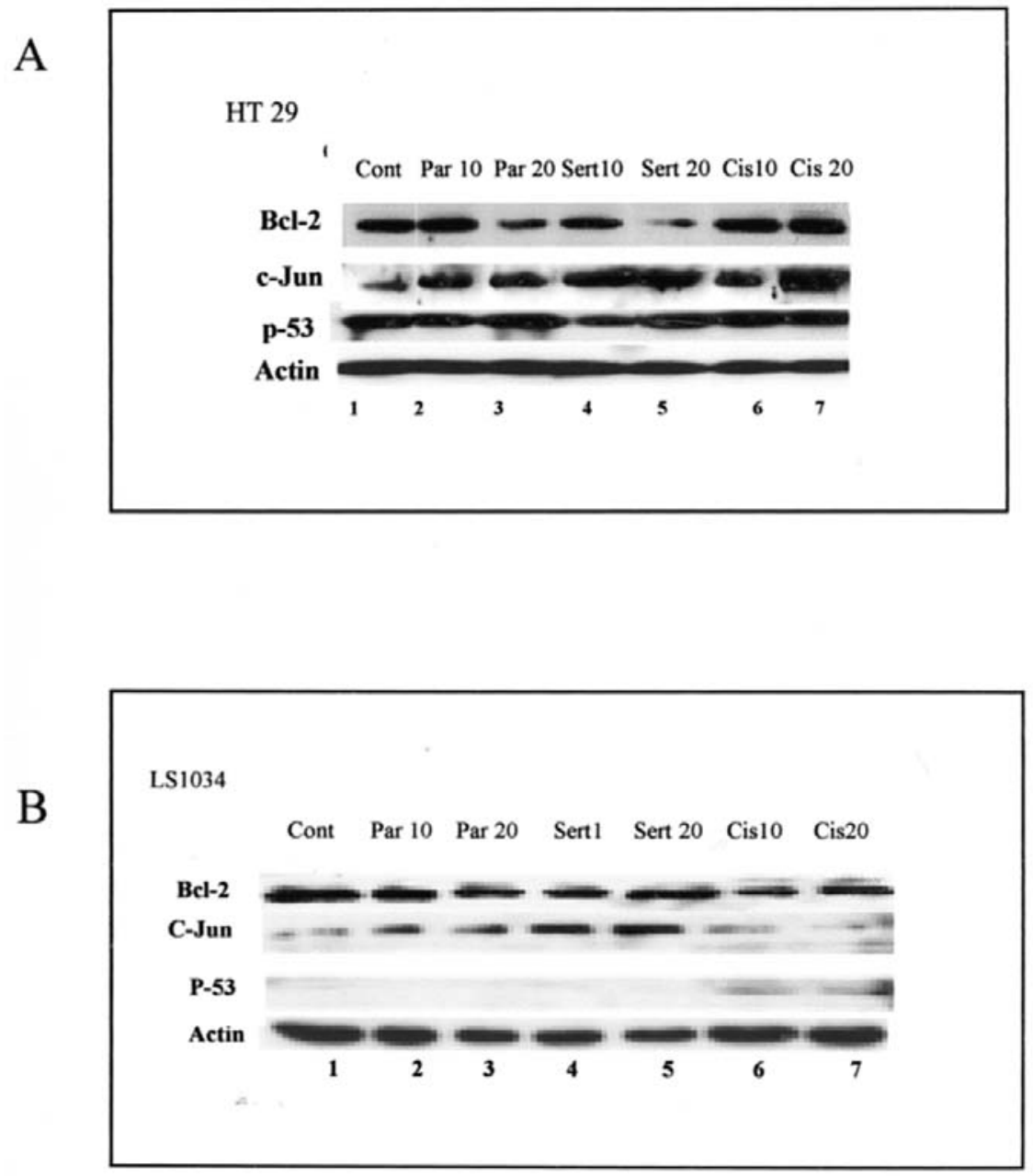

Figure 6. Western blot analysis of Bcl-2, c-Jun and p-53 proteins in HT29 (A) and LS1034 cells (B) 24 h after exposure to paroxetine, sertraline or a cytotoxic agent (cisplatin or doxorubicin at 10 and $20 \mu \mathrm{M}$ ). B-actin was used as a control for the protein level. 
A
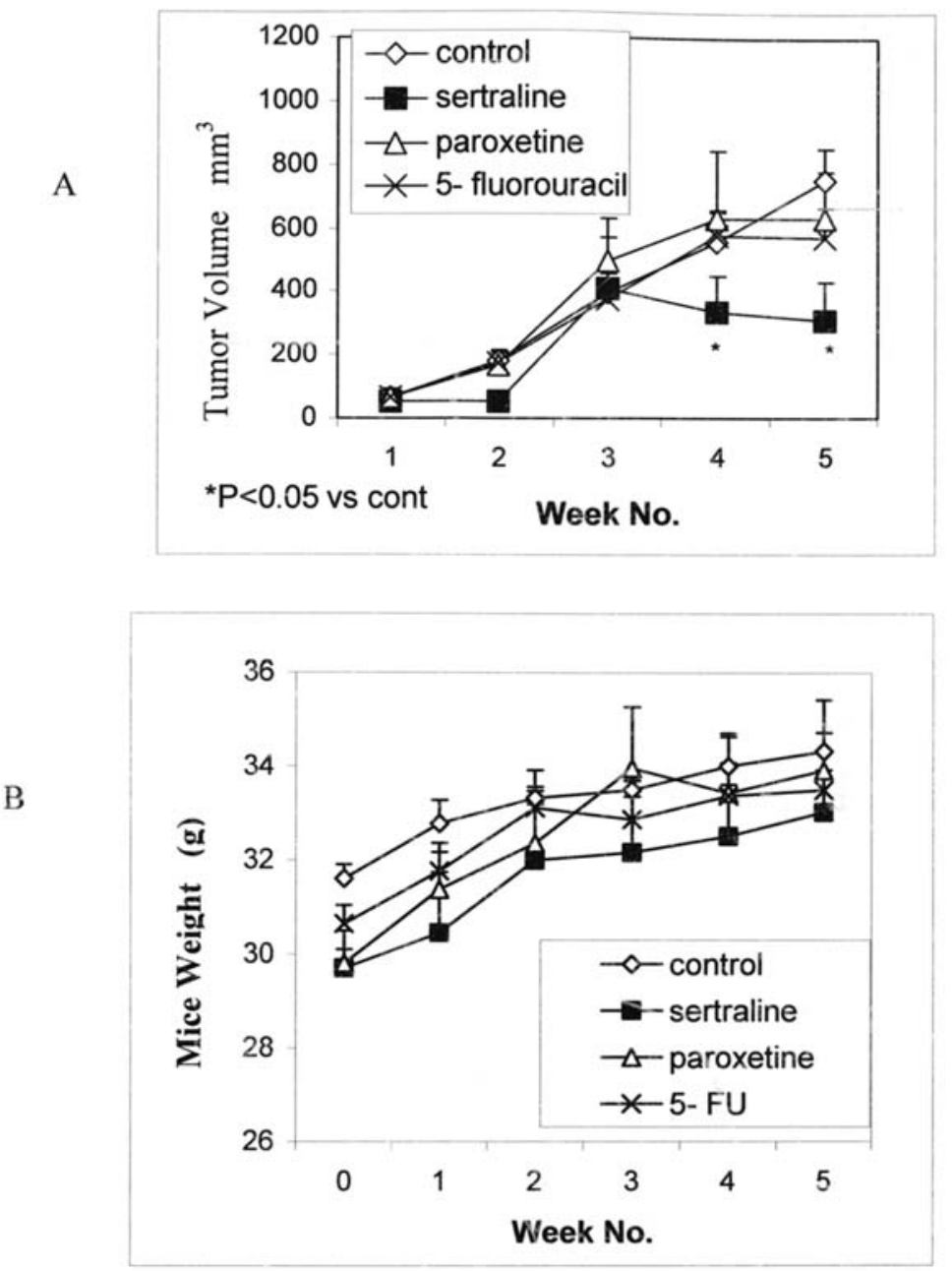

Figure 7. The in vivo data of $\mathrm{CD} 1$ nude mice treated i.p. with sertraline paroxetine or 5-FU beginning 8 days after cell inoculation. Tumor volume (A) and body weight (B) were measured once a week. Each point is the mean \pm SEM of 6 animals.

Table II. Tumor volume variation in the different treatment groups after 5 weeks.

\begin{tabular}{lcccc}
\hline & \multicolumn{2}{c}{ Tumor size } & Large $>500 \mathrm{~mm}$ & P vs. control \\
\cline { 2 - 5 } Drug & Small $<250 \mathrm{~mm}$ & Medium $<500 \mathrm{~mm}$ & 6 & \\
\hline Control & 0 & 1 & 1 & $>0.03$ \\
Sertraline & 3 & 2 & 4 & \\
Paroxetine & 0 & 2 & 3 & \\
$5-\mathrm{FU}$ & 0 & 3 & & \\
\hline
\end{tabular}

(Fig. 7B) and each agent was well-tolerated. After autopsy, tumors were dissected and homogenized individually and lysates determined for c-Jun, Bcl-2 and p53. The results (Fig. 8) demonstrate variability in the individual levels of each protein. An increase in c-Jun was noted in the SSRI-treated groups, while only 5-FU showed an increase in Bcl-2.

\section{Discussion}

Our results provide evidence that the widely used SSRIs, paroxetine and sertraline, induce a marked inhibition of cell survival, anti-proliferative activity and apoptosis in human colon carcinoma cells possessing mutated or wild-type p53 expression (HT29 and LS1034, respectively). Sertraline showed the most potent inhibition of viability of HT29 cells with $\mathrm{IC}_{50}$ of $14.7 \mu \mathrm{M}$ followed by paroxetine, clomipramine and fluoxetine, while the noradrenaline reuptake inhibitor, reboxetine, showed no effect on cell survival or apoptosis. When compared to the anti-neoplastic agent doxorubicin using the $\left[{ }^{3} \mathrm{H}\right]$-thymidine incorporation test, sertraline and paroxetine demonstrated a weaker anti-proliferative effect, yet their effect was comparable to other commonly used cytotoxic agents such 


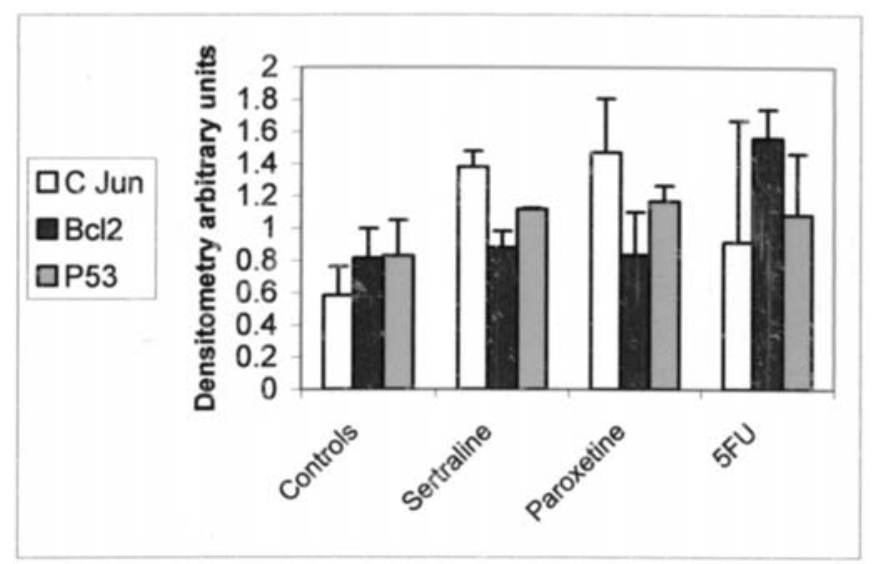

Figure 8. Densitometry analysis of c-Jun, Bcl-2 and p53 in individual tumors dissected from a mouse cancer model (each column represents the mean and SEM of 6 determinations).

as vincristine and cisplatin (Fig. 2). Conversely, in the MDR human colon carcinoma LS1034 cells, the effect of the active antidepressants was completely preserved with $\mathrm{IC}_{50}$ levels of 13.1 $\mu \mathrm{M}$ for sertraline, which was different from doxorubicin and 5-FU, which showed mild or no activity. These results imply that the active antidepressants operate by a mechanism that circumvents MDR in colon cancer cells. The development of resistance of cancer cells to drugs is related to the existence of efflux transporter Pgp. Drug resistance can be circumvented by agents that inhibit Pgp (36). With regard to the activity of antidepressants on Pgp, it was found that several antidepressants including citalopram, fluoxetine, fluvoxamine, paroxetine, reboxetine, sertraline and venlafaxine and their major metabolites desmethylcitalopram, norfluoxetine, paroxetine-metabolite and desmethylsertraline possess an inhibitory effect on Pgp at similar concentrations as quinidine (a classic Pgp inhibitor) in two models: cancer MDR1 cells, and a model for the blood-brain barrier. Sertraline, desmethylsertraline and paroxetine were found to be most potent (25). Moreover, Peer et al (27) provided evidence that the antidepressant fluoxetine enhanced responses to chemotherapy in syngeneic and in human xenograft mouse tumor models, by the inhibition of the MDR extrusion pump Pgp. The cytotoxic effect of the active SSRIs sertraline and paroxetine was mediated by apoptosis, evidenced by the activation of the caspase- 3 enzyme accompanied by a dosedependent cell cycle arrest at the G0/G1 phase and a decrease in the $\mathrm{S}$ phase. Caspase-3 is a key component involved in apoptosis (34) and its levels appear to have a prognostic value in colon cancer (37). We previously showed that the SSRIs paroxetine and fluoxetine stimulated caspase- 3 activity in glioma and neuroblastoma cell lines (12) and a similar effect on caspase- 3 and cell cycle was found for the phenothiazines class of the neuroleptics, suggesting a possible common mechanism of action (33). With regard to the transcription factors and oncogenes involved in the SSRIs-induced apoptosis, we found that paroxetine and sertraline stimulated the expression of c-Jun. These results support our previous observation of early stimulation of p-c-Jun by paroxetine and fluoxetine in rat glioma cells (12). The JNK pathway mediates apoptotic death in response to a variety of stressful stimuli
(14). In this study, we demonstrated a differential effect on the c-Jun protein in the two cell lines induced by the cytotoxic agents cisplatin and doxorubicin. Whereas in the sensitive HT29 cells, the cytotoxic agent cisplatin induced an increase in c-Jun, in the resistant line, LS1034, doxorubicin did not modify it, suggesting a potential role of the MAPK cJun pathway in the development of drug resistance. Yet, additional comparative studies with several cytotoxic agents in the two cell lines are needed to support this hypothesis. Another study revealed proapoptotic effect of the cytotoxic agent DMNQ-S52 in Lewis lung carcinoma cells by the stimulation of JNK that triggered caspase-3 activation (38). Furthermore, in our study we found increased c-Jun expression in the 'in vivo' HT29 tumors. Other major genes involved in apoptosis regulation are the anti-apoptotic Bcl-2 and its family members, and p53, the tumor suppressor gene, which in its mutated type signals for defective apoptosis and tumor progression in various types of cancers including most types of colorectal cancer (6). The mutated p53 is overexpressed in tumor cells and indicates an unfavorable prognosis (39). P53 is mutated in HT29 cells and was suppressed by the two SSRIs at $10 \mu \mathrm{M}$ though not with the $20 \mu \mathrm{M}$, suggesting a possible bell shape effect of the drugs on mutated p53. However, it appears in its wild-type in the LS1034 cell line where p53 is negative $(28,29)$. In these MDR cells, SSRIs tended to further reduce p53, while doxorubicin increased its expression. Sertraline and paroxetine (at $20 \mu \mathrm{M}$ ) inhibited the expression of the anti-apoptotic protein Bcl-2 in HT29 and in the LS1034 cells, $24 \mathrm{~h}$ after exposure. A similar effect was found by cisplatin in HT29 cells, although not by doxorubicin in LS1034. In the cancer-bearing mice, no significant effect was observed on the expression of either Bcl-2 or p53 by the SSRIs due probably to the lack of effective concentrations in the blood and to the high variability seen in the animals.

Serotonin was previously reported to affect cell proliferation, maturation and apoptosis in different cell types including colorectal carcinoma and drugs such as fluoxetine and citalopram, which were reported to retard the growth of two out of three lines of human colonic tumors in immunedeprived mice $(40,41)$. Thus, the role of serotonin in drug activity cannot be ruled out in the in vivo models. However, the vast difference in the effect of various antidepressants, each possessing the effective inhibition of the serotonin transporter and our previous results showing the direct in vitro effect of paroxetine on the gene expression of proteins and transcription factors involved in cell proliferation in human isolated T lymphocytes, suggests a serotonin-independent direct proapoptic activity (19).

All in all our results are in line with recent data showing a marked proapoptotic effect of certain antidepressants, tricyclic and SSRIs, in different cell lines. The tricyclic antidepressants imipramine and desipramine caused apoptosis in HT29 cells accompanied by cell cycle arrest at the G0/G1 phase (42). Our results in xenografted nude mice show that the antidepressant sertraline, though not paroxetine, induced a significant inhibition of HT29 subcutaneous tumor volume mainly from the 3 rd week of therapy in male CD1 nude mice. This effect was even more pronounced than that produced by the same dose of 5-FU. When animals were 
divided into groups by their tumor volume, 6/7 control animals presented big tumors $\left(>500 \mathrm{~mm}^{3}\right)$, while only 1 animal in the sertraline group showed a big tumor mass and 3 revealed small tumors $\left(<250 \mathrm{~mm}^{3}\right)$ (Table I). The drugs were welltolerated and there was no difference in body weight gain or in general behavior in any of the groups. These data are in line with a recent epidemiological study demonstrating that the use of SSRIs at high doses up to 5 years before diagnosis is associated with a decreased incidence (odd ratio 0.7) of colorectal cancer (19). Long-term SSRI use was not associated with the increased risk of ovarian cancer (43) and of breast cancer (44). Yet, the use of sertraline $(50 \mathrm{mg} /$ day) in patients with advanced cancer resulted in the failure of the drug to improve symptoms, wellbeing or survival of these patients (20). These results could be related to the low dose of the drug and the advanced stages of the cancer.

Therapeutic doses of SSRI (including sertraline) administered for depression and anxiety-related disorders induce plasma concentrations of $<1 \mu \mathrm{M}$ (45), which is a subeffective dose for anti-proliferative activity. We believe that any modification of formulation or the use of higher doses could potentially increase the efficacy of the active SSRIs in the treatment of cancer. Since SSRIs are widely used to treat cancer patients for depression (46), the selection of antidepressants with anti-proliferative activity seems to offer potential therapeutic benefits.

\section{Acknowledgements}

We thank Perrigo Pharmaceuticals Israel and the Chief Scientists Office, Israel, for their support.

\section{References}

1. Jemal A, Murray T, Samuels A, Ghafoor A, Ward E and Thun MJ: Cancer Statistics, 2003. CA Cancer J Clin 53: 5-26, 2003.

2. Rupnarain C, Dlamini Z, Naicker S and Bhoola K: Colon cancer: genomics and apoptotic events. Biol Chem 385: 449-464, 2004.

3. Leichman CG, Fleming TR, Muggia FM, et al: Phase II study of fluorouracil and its modulation in advanced colorectal cancer. A Southwest Oncology Group Study. J Clin Oncol 13: 1303-1311, 1995.

4. Reed JC, Cuddy M, Slabiak T, Croce CM and Nowell PC: Oncogenic potential of $\mathrm{Bcl}-2$ demonstrated by gene transfer. Nature 336: 259-261, 1988

5. Jager R, Herzer U, Schenkel J and Weiher H: Overexpression of $\mathrm{Bcl}-2$ inhibits alveolar cell apoptosis during involution and accelerates c-myc-induced tumorigenesis of the mammary gland in transgenic mice. Oncogene 15: 1787-1795, 1997.

6. Han HS, Park YM and Hwang TS: Differential expression of $\mathrm{Bcl}-2, \mathrm{Bcl}-\mathrm{X}_{\mathrm{L}}$ and $\mathrm{p} 53$ in colorectal cancer. J Gastroenterol Hepatol 21: 1108-1114, 2006.

7. Bell SM, Scott N, Cross D, et al: Prognostic value of p53 overexpression and $c$-Ki-ras gene mutations in colorectal cancer. Gastroenterology 104: 57-64, 1993.

8. Hibi M, Lin A, Smeal T, Minden A and Karin M: Identification of an oncoprotein- and UV-responsive protein kinase that binds and potentiates the c-Jun activation domain. Genes Dev 7: 2135-2148, 1993.

9. Li F, Meng L, Żhou J, et al: Reversing chemoresistance in cisplatin-resistant human ovarian cancer cells: a role of c-Jun NH2-terminal kinase 1. Biochem Biophys Res Commun 335: 1070-1077, 2005.

10. Sebolt-Leopold JS, Dudley DT, Herrera R, et al: Blockade of the MAP kinase pathway suppresses growth of colon tumors in vivo. Nat Med 5: 810-816,1999.

11. Nordenberg J, Fenning E, Landau M, Weizman R and Weizman A: Effect of psychotrophic drugs on cell proliferation and differentiation. Biochem Pharmacol 58: 1229-1236, 1999.
12. Levkovitz Y, Gil-Ad I, Zeldich E, Dayag M and Weizman A: Differential induction of apoptosis by antidepressants in glioma and neuroblastoma cell lines: evidence for p-c-Jun, cytochrome c, and caspase-3 involvement. J Mol Neurosci 27: $29-42,2005$.

13. Chang L and Karin M: Mammalian MAP kinase signalling cascades. Nature 410: 682-685, 2001.

14. Estus S, Zaks WJ, Freeman RS, Gruda M, Bravo R and Johnson EM: Altered gene expression in neurons during programmed cell death: identification of c-jun as necessary for neuronal apoptosis. J Cell Biol 127: 1717-1727, 1994.

15. Mesner PW, Epting CL, Hegarty JL and Green SH: A timetable of events during programmed cell death induced by trophic factor withdrawal from neuronal PC12 cells. J Neurosci 5: 7357-7366, 1995.

16. Abdul M, Logothetis CJ and Hoosein NM: Growth inhibitory effects of serotonin uptake inhibitors on human prostate carcinoma cell lines. J Urol 154: 247-250, 1995.

17. Xia Z, Bergstrand A, DePierre JW and Nassberger L: The antidepressants imipramine, clomipramine, and citalopram induce apoptosis in human acute myeloid leukemia HL-60 cells via caspase-3 activation. J Biochem Mol Toxicol 13: 338-347, 1999.

18. Serafeim A, Holder MJ, Grafton G, et al: Selective serotonin reuptake inhibitors directly signal for apoptosis in biopsy-like Burkitt lymphoma cells. Blood 101: 3212-3219, 2003.

19. Taler M, Gil-Ad I, Lomnitski L, et al: Immunomodulatory effect of selective serotonin reuptake inhibitors (SSRIs) on human T lymphocyte function and gene expression. Eur Neuropsychopharmacol 17: 774-780, 2007.

20. Rossetti M, Frasnelli M, Tesei A, Zoli W and Conti M: Cytotoxicity of different selective serotonin reuptake inhibitors (SSRIs) against cancer cells. J Exp Ther Oncol 6: 23-29, 2006

21. Chou CT, He S and Jan CR: Paroxetine-induced apoptosis in human osteosarcoma cells: Activation of p38 MAP kinase and caspase-3 pathways without involvement of $\left[\mathrm{Ca}^{2+}\right]_{\mathrm{i}}$ elevation. Toxicol Appl Pharmacol 218: 265-273, 2007.

22. Xu W, Tamim H, Shapiro S, Stang MR and Collet JP: Use of antidepressants and risk of colorectal cancer: a nested casecontrol study. Lancet Oncol 7: 301-308, 2006.

23. Stockler MR, O'Connell R, Nowak AK, et al: Effect of sertraline on symptoms and survival in patients with advanced cancer, but without major depression: a placebo-controlled double-blind randomised trial. Lancet Oncol 8: 603-612, 2007.

24. Ling V: Multidrug resistance: molecular mechanisms and clinical relevance. Cancer Chemother Pharmacol 40: S3-S8, 1997.

25. Weiss J, Dormann SM, Martin-Facklam M, et al: Inhibition of P-glycoprotein by newer antidepressants. J Pharmacol Exp Ther 305: 197-204, 2003.

26. Gil-Ad I, Shteif B, Levkovitz Y, et al: Phenothiazines induce apoptosis in a B16 mouse melanoma cell line and attenuate in vivo melanoma tumor growth. Oncol Rep 15: 107-112, 2006.

27. Peer D, Dekel Y, Melikhov D and Margalit R: Fluoxetine inhibits multidrug resistance extrusion pumps and enhances responses to chemotherapy in syngenic and in human xenograft tumor models. Cancer Res 64: 7562-7569, 2004.

28. Li CY, Suardet L and Little JB: Potential role of WAF1/Cip1/p21 as a mediator of TGF-beta cytoinhibitory effect. J Biol Chem 270: 4971-4974, 1995.

29. Suardet L, Gaide AC, Calmes JM, Sordat B, Givel JC, Eliason JF and Odartchenko N: Responsiveness of three newly established human colorectal cancer cell lines to transforming growth factors beta 1 and beta 2. Cancer Res 52: 3705-3712 1992.

30. Borenfreund $\mathrm{E}$ and Puerner JA: A simple quantitative procedure using monolayer cultures for cytotoxic assays (HTD/NR -90). J Tissue Cult Methods 9: 7-9, 1984.

31. Ahmed SA, Gogal RM and Walsh JE: A new rapid and simple non-radioactive assay to monitor and determine proliferation of lymphocytes: an alternative to $\{3 \mathrm{H}\}$ thymidine incorporation assay. J Immunol Methods 170: 211-224, 1994.

32. Nicolletti I, Migliorato G, Pagliacci MC, Grimsani F and Riccardi C: A rapid and simple method for measuring thymocyte apoptosis by propidium-iodide staining and flow cytometry. $\mathbf{J}$ Immunol Methods 139: 271-279, 1991.

33. Gil-Ad I, Shtaif B, Levkovitz Y, Dayag M, Zeldich E and Weizman A: Antiproliferative activity of phenothiazines in neuroblastoma and glioma cell-lines. Evidence for apoptotic mechanism and relevance to brain cancer therapy. J Mol Neurosci 22: 189-198, 2004. 
34. Bossy-Wetzel E, Newmeyer DD and Green DR: Mitochondrial cytochrome $c$ release in apoptosis occurs upstream of DEVDspecific caspase activation and independently of mitochondrial transmembrane depolarization. EMBO J 17: 37-49, 1998.

35. Kaur M, Singh RP, Gu M, Agarwal R and Agarwal C: Grape seed extract inhibits in vitro and in vivo growth of human colorectal carcinoma cells. Clin Cancer Res 12: 6194-6202, 2006.

36. Lehne G: P-glycoprotein as a drug target in the treatment of multidrug resistant cancer. Curr Drug Targets 1: 85-99, 2000.

37. De Oca J, Azuara D, Sanchez-Santos R, et al: Caspase-3 activity, response to chemotherapy and clinical outcome in patients with colon cancer. Int J Colorectal Dis (In press).

38. Lee SJ, Sakurai H, Koizumi K, et al: MAPK regulation and caspase activation are required in DMNQ S-52 induced apoptosis in Lewis lung carcinoma cells. Cancer Lett 233: 5767, 2005

39. Pricolo VE, Finkelstein SD, Hansen K, Cole BF and Bland KI: Mutated p53 gene is an independent adverse predictor of survival in colon carcinoma. Arch Surg 132: 371-374, 1997.

40. Tutton PJ and Barkla DH: Influence of inhibitors of serotonin uptake on intestinal epithelium and colorectal carcinomas. Br J Cancer 46: 260-265, 1982.
41. Azmitia EC: Modern views on an ancient chemical: serotonin effects on cell proliferation, maturation, and apoptosis. Brain Res Bull 56: 413-424, 2001.

42. Arimochi H and Morita K: Characterization of cytotoxic actions of tricyclic antidepressants on human HT29 colon carcinoma cells. Eur J Pharmacol 10: 17-23, 2006.

43. Moorman PG, Berchuck A, Calingaert B, Halabi S and Schildkraur JM. Antidepressant medication use [corrected] and risk of ovarian cancer. Obstet Gynecol 105: 725-730, 2005.

44. Coogan PF, Palmer JR, Strom BL and Rosenberg L: Use of selective serotonin reuptake inhibitors and the risk of breast cancer. Am J Epidemiol 162: 835-838, 2005.

45. Kirchherr $\mathrm{H}$ and Kuhn-Velten WN: Quantitative determination of forty-eight antidepressants and antipsychotics in human serum by HPLC tandem mass spectrometry: A multi-level, single-sample approach. J Chromatogr B 843: 100-113, 2006.

46. Goodnick PJ and Hernandez M: Treatment of depression in comorbid medical illness. Expert Opin Pharmacother 1: 1367-1384, 2000 . 